\title{
AVANCES Y RETROCESOS EN EL RECONOCIMIENTO DEL TERRITORIO DE LOS AYOREOS BOLIVIANOS
}

\author{
ADVANCES AND SETBACKS IN THE RECOGNITION OF THE TERRITORY OF \\ THE BOLIVIAN AYOREOS
}

\author{
Yaneth Katia Apaza Huanca*
}

RESUMEN: Los ayoreos bolivianos enfrentan una lucha por el reconocimiento de su territorio, su demanda jurídica se inicia al final de los ochenta; en 1999 a través de la Ley No 1715 logran que cuatro de sus comunidades sean reconocidas como Tierras Comunitarias de Origen (TCO). El año 2009, la nueva Constitución cambiará el nombre de TCO al de Territorio Indígena Originario Campesino (TIOC) esta nueva denominación trae conflictos en su reconocimiento territorial y avasallamiento. Aproximadamente hace 20 años que no logran ningún tipo de reconocimiento territorial, aunque la Constitución les reconoce como "nación" y el dominio ancestral sobre sus territorios.

ABSTRACT: The Bolivian ayoreos face a struggle for the recognition of their territory, their legal demand began at the end of the eighties; in 1999 through Law No. 1715 they achieved the recognition of four of their communities as Community Lands of Origin (TCO). In 2009, the new Constitution would change the name of the TCO to the Indigenous Territory of Origin Peasant (TIOC). It has been approximately 20 years since they achieved any kind of territorial recognition, although the Constitution recognizes them as a "nation" and the ancestral domain over their territories.

PALABRAS CLAVE: Ayoreos bolivianos, territorio, Tierras Comunitarias de Origen (TCO), Territorio Indígena Originario Campesino (TIOC).

KEYWORDS: Bolivian ayoreos, territory, Communal Lands of Origin (TCO), Indigenous Territory of Origin Peasant (TIOC).

Fecha de recepción: 04/06/2021

Fecha de aceptación: 29/03/2021

doi: https://doi.org/10.20318/universitas.2021.6192

\footnotetext{
* Doctora en Estudios Avanzados en Derechos Humanos, abogada e investigadora independiente. E-mail: vivanka333@gmail.com
} 


\section{1.- INTRODUCCIÓN}

Los ayoreos o ayoreode (plural masculino) es la autodenominación bajo la que se reconocen, significa "hombre o gente verdadera1", ellos son una de las 36 culturas ancestrales que el Estado plurinacional de Bolivia ha reconocido como "nación" a través de su idioma el zamuco conforme al art. 2 de la Constitución Política del Estado del año 2009, esto es, se reconoce su identidad y su territorio; sin embargo, pese a esta afirmación jurídica, el mismo no es tangible en la realidad pues su territorio continua siendo avasallado por campesinos, ganaderos, madereros, agropecuarios y migrantes interculturales; por otra, este reconocimiento es parcial porque no tienen el dominio sobre los recursos no renovables, debido a las restricciones constitucionales y limitaciones normativas específicas.

A lo largo de los años se ha observado que su reivindicación territorial tiene dos perspectivas: la histórica y la jurídica; la histórica se inicia a fines de la década de los años ochenta del siglo anterior, a través de la creación de organizaciones que los representen en sus demandas de reconocimiento territorial y las que han tenido representación importante, también han acudido a otra forma notoria de manifestación para sus reivindicaciones: las "marchas indígenas" desde sus lugares de orígenes hasta las ciudades metrópolis; hasta el momento se han compatibilizado ocho marchas desde la década de los años noventa, la última en 2011, estas marchas no solamente la realizaron los ayoreos sino todo el conjunto de naciones ancestrales que habitan el oriente boliviano. Sin embargo, la más importante fue la "II Marcha por el territorio, los derechos de participación política y el desarrollo" (1996), en la que lograron que cuatro de sus comunidades sean reconocidas posteriormente, como Tierras Comunitarias de Origen (TCO) en 1999.

Por otra parte, la perspectiva jurídica para la demanda territorial, ha tenido fases el cual ha abarcado distintas legislaciones agrarias y constitucionales; en un primer momento se inicia con una demanda denominada "Territorio Tradicional Ayoreo" al amparo de la Reforma Agraria de 1953 convertida en ley en 1956 (el cual no prosperó); posteriormente, en el marco de la Ley del Servicio Nacional de Reforma Agraria Ley No 1715 de 1996, se logró beneficiar a esta "nación" con el reconocimiento de sus tierras ancestrales denominándolas como Tierras Comunitarias de Origen (TCO) en las comunidades de Zapocó, Guaye-Rincón del Tigre, Santa Teresita y Tobité II en el año 1999, permitiendo el reconocimiento de sus espacios geográficos, su hábitat

\footnotetext{
1 Mercedes Nostas, Carmen Elena Sanabria Salmón, Detrás del cristal con que se mira: Mujeres ayoreas-ayoredie, órdenes normativos e interlegalidad [10 ed., 2009] 13.

<http://www.coordinadoradelamujer.org.bo/observatorio/archivos/publicaciones/lib ro mujeres ayoreasayoredie ordenes normativos e interlegalidadc 273.pdf> consultado el 31 mayo 2020.
} 
a los cuales han tenido tradicionalmente acceso, y donde mantienen y desarrollan sus propias formas de organización económica, social y cultural, considerándose además, como inalienable, indivisible, irreversible, colectivo, inembargable e imprescriptible (art. 41 inc. 5, Ley No 1715) todo esto bajo el amparo del Convenio No 169 de la Organización Internacional del Trabajo convertida en Ley de la República de Bolivia en 1991 y bajo la presión de una reforma constitucional de 1994, en la que se reconocía que Bolivia era un Estado pluricultural y multiétnico.

Los años 2006-2007, Bolivia llevó adelante la Asamblea Constituyente, dando lugar a la refundación del Estado boliviano a través de una nueva Constitución Política del Estado el año 2009, en la que se dio prioridad a las mayorías poblacionales denominadas "indígenas ${ }^{2 "}$ dándose amplitud y reconocimiento a los derechos de las 36 naciones ancestrales reconocidas dentro de un Estado que se declaró plurinacional ${ }^{3}$, dentro de estas naciones reconocidas se encontraban los ayoreos; sin embargo, pese a todos los derechos otorgados en la nueva Constitución, considerándose además de adelantada, contradictoriamente su reconocimiento territorial se postergó nuevamente, y al contrario este se vio acelerada a favor de las medianas y grandes empresas, campesinos migrantes, interculturales, puesto que la norma fundamental reconoce y garantiza los derechos adquiridos por terceros propietarios con predios -en lo que denominará- como Territorio Indígena Originario Campesino (TIOC), así esta forma de garantizar el derecho propietario de un tercero sobre la TIOC, trae dificultades jurídicas actuales que en los hechos se translucen en avasallamiento territorial hacia los ayoroes.

Por otra parte, el reconocimiento que se hizo como TCO en 1999 a las comunidades ayoreas sufre cierto menoscabo porque la nueva legislación constitucional solo reconoce a la TIOC a efectos de derechos autonómicos la cual va muy ligado a la libre determinación y al propio gobierno, es así que para este cambio de denominación de TCO a TIOC se debe ir a un proceso administrativo previo.

Así, el presente artículo se desarrolló en dos partes, en la primera parte, se dio a conocer la identidad de los ayoreos bolivianos, en ese contexto se mostró su ubicación geográfica, la densidad demográfica, y la historia de su reivindicación territorial desde las perspectivas mencionadas la: histórica y jurídica. La segunda parte, y de forma más puntual se hizo hincapié en algunas causas por las que se ven obstaculizadas sus demandas de reconocimiento territorial (causas de

\footnotetext{
2 Aunque es el denominativo bajo el que se reconoce a los ayoreos y otras naciones ancestrales en Bolivia, este no es identificativo de su identidad, al contrario, es una denominación externa de la cual intentan salir.

3 El partido de gobierno desde el 2006 fue el movimiento al Socialismo-Instrumento Político por la Soberanía de los Pueblos (MAS-IPSP), el cual ha gobernado hasta la actualidad, con la única interrupción de la crisis política que ocurrió el año 2019 y que dio lugar al gobierno constitucional de Jeanine Añez hasta el 2020. Actualmente no existen cambios en la legislación en favor de los ayoreos.
} 
hecho y de derecho) finalmente, se culminó con las conclusiones siendo una de las más importantes que cualquiera sea la forma de gobierno (neoliberal o plurinacional) no se permite el avance en sus demandas territoriales, debido a intereses privados muy ligado a la propiedad mercantil de la tierra. Es decir, que la tensión individualismo versus comunidad es real y muy latente.

\section{1.- Los ayoreos en Bolivia, una constante lucha de existencia}

En Bolivia los ayoreos son considerados una población minoritaria puesto que 2189 personas se han reconocido como tal ${ }^{4}$, sin embargo, según el Informe del Grupo Internacional de Trabajo para Asuntos Indígenas (IWGIA) el número total de integrantes serían 5600; de ellos 3000 se encontrarían en Bolivia y 2600 en Paraguay ${ }^{5}$, también existen ayoreos en aislamiento voluntario; es decir, sin contacto. El territorio tradicional ayoreo abarcaría una extensión cercana a los 33 millones de hectáreas entre Bolivia y Paraguay en el norte del Gran Chaco 6

Los ayoreos en su mayoría han sido nómadas, aunque posteriormente fueron sedentarizados, ellos están conformados por siete clanes: cikenoi, etakoíri, pikaneraé, dosapéi, kutamuahái, nurumíhi y posonhái7. Su primer contacto fue con los españoles en 1537 en la región del Chaco, otros contactos no pacíficos fueron en 1546, 1547 y 1559 durante la época de la conquista.

Durante la época de la colonia, los jesuitas tomaron contacto intentando que fueran incorporados a la Misión Chiquitana entre 1691 y 1724 , posteriormente entre 1711 y 1724 se logró agrupar a varios clanes zamuco y fundar la Misión de San Ignacio de los zamucos en el centro del Chaco Boreal (1724-1745); sin embargo, con la expulsión de los jesuitas en 1767 los ayoreos volvieron a sus patrones culturales tradicionales ${ }^{8}$.

\footnotetext{
${ }^{4}$ Estado Plurinacional de Bolivia, Censo de población y vivienda 2012 Bolivia $\begin{array}{lllllll}\text { Características de la Población [2015] } & 29 & \text { y } & 30\end{array}$ $<$ https://www.ine.gob.bo/index.php/publicaciones/censo-de-poblacion-y-vivienda2012-caracteristicas-de-la-poblacion/> consultado el 30 octubre 2019.

5 Ibíd., 13.

6 Miguel Lovera y otros, La situación de los ayoreos aislados en Bolivia y en las zonas transfronterizas con Paraguay [Informe 2016, 2017] 5 <https://www.iniciativaamotocodie.org/wp-content/uploads/2019/08/InformeAisladosZonaFronteraPYBO.pdf> consultado el 10 de abril de 2020.

7 José Zanardini, "Vida y misterio de los indios Moros Ayoreos" [1981] 16

Suplemento antropológico, 167-185

<http://www.bibvirtual.ucb.edu.bo:8000/etnias/digital/106001469.pd >consultado el 31 de mayo de 2020.

8 Guillermo Schmeda-Hirschmann, "Etnobotánica Ayoreo. Contribución al estudio de 1a flora y vegetación del Chaco" [1998] 53 Candollea 1-50 $<$ https://www.researchgate.net/profile/Guillermo SchmedaHirschmann/publication/277204260 Etnobotanica Ayoreo Contribucion al estudio de la flora y vegetacion del Chaco/links/55b62a1808aed621de03169e/Etnobot
} 
Posteriormente con el nacimiento de los Estados, los ayoreos vivieron en territorios aislados en Bolivia y Paraguay, así mantuvieron su identidad y territorio hasta el descubrimiento del petróleo en su territorio, esto dio lugar a la guerra del Chaco entre Bolivia y Paraguay (1932-1935) entonces los ayoreos se encontraron en el centro de la contienda, obligándoles a abandonar su territorio. Schmeda Hirschmann menciona que los conflictos interétnicos, los choques con los militares y compañías petroleras les obligaron a tomar contacto nuevamente asentándose en misiones ${ }^{9}$. También la construcción del ferrocarril Santa Cruz-Corumba (1938-1953) posibilitó la penetración a su territorio ${ }^{10}$.

A comienzos de la década de 1940, se volvió a tomar contacto con ellos y en 1947 se produjo un contacto más permanente a través de las misiones norteamericanas New Tribes quienes fueron los primeros en establecer contacto con los ayoreos silvestres, intentando sedentarizarlos, este proceso fue complejo y largo hasta que se logró establecerlos ${ }^{11}$, a partir de este se fundó Tobité el primer asentamiento ayoreo permanente. En 1950 la Misión Sudamericana creó Zapocó; en 1952 la Misión Bautista Lettus fundó Rincón del Tigre-Guayé. Una Misión Católica a cargo de Elmar Klingler fundo Santa Teresita en $1953^{12}$. Estos asentamientos permanentes a través de las misiones serán reconocidos en 1999 como territorio de los ayoreos por el Estado boliviano; sin embargo, otras comunidades ayoreas tales como: Puesto Paz, Poza Verde, Urucú, Motacú Santiago, El Carmen Rivero, Guidai Ichai, aunque tienen el título a nombre de las misiones evangélicas y católicas no han logrado ser tituladas como territorio ayoreo ${ }^{13}$.

En Bolivia actualmente se ubican en el Chaco boliviano, el cual comprende los departamentos de Chuquisaca, Tarija y Santa Cruz, y

anica-Ayoreo-Contribucion-al-estudio-de-la-flora-y-vegetacion-del-

Chaco.pdf>consultado el 31 de mayo de 2020.

${ }^{9}$ Ibíd., 2.

10 Administradora Boliviana de Carreteras, Proyecto carretero del corredor conector de Santa Cruz-SCRCCP plan de pueblos indígenas (PPI) comunidades indígenas Chiquitanas y Ayoreo de del área de influencia del proyecto [2015] 14 $<$ http://documents.worldbank.org/curated/en/418971468284660552/pdf/SFG1743 -REVISED-IPP-SPANISH-P152281-Box396261B-PUBLIC-Disclosed-5-25-

2016.pdf >consultado el 20 de abril de 2020.

11 Marcelo Bórmida, Ergon y Mito: Una hermenéutica de la cultura material de los Ayoreo del Chaco Boreal [CIAFIC 2005] 10

<http://www.ciafic.edu.ar/documentos/Archivos III 1 2005.pdf $>$ consultado el 4 de abril de 2020.

12 Leonardo Tamburini, Atlas Sociopolítico sobre los territorios indígenas en las tierras bajas de Bolivia [IWGIA, 2019] 246, 250 y 254

<https://www.iwgia.org/images/documentos/Libros/ATLAS\%202019.pdf>

consultado el 1 de junio de 2020.

13 Enrique Herrera y otros, Identidades y territorios indígenas estrategias identitarias de los tacana y ayoreo frente a la ley INRA [Ana María Lema, 2003] 62 $<$ http://www.pieb.com.bo/2016/BPIEB/BPIEB 1656 Identidades.pdf $>$ consultado el 1 junio 2020. 
en este último departamento ellos se encuentran en las provincias: Germán Busch, Ñuflo de Chávez, Chiquitos, Andrés Ibáñez y Cordillera, en estas provincias se hallan las cuatro comunidades reconocidas como Tierras Comunitarias de Origen (TCO): Zapocó, Guaye-Rincón del Tigre, Santa Teresita, Tobité II, todas en la subregión Chiquitana, además ellos viven en 27 comunidades, 16 son asentamientos en el área rural y 9 en ciudades intermedias del departamento de Santa Cruz $^{14}$. A continuación, lo que se muestra son dos cuadros, el cuadro No 1 nos muestra la fecha de fundación de los asentamientos ayoreos por las misiones evangélicas y católicas, las hectáreas y fechas de titulación de parte del Estado boliviano. En el cuadro No 2 se muestra las comunidades ayoreas no reconocidas, aun cuando algunas tienen títulos.

\section{Cuadro No 1: Cronograma histórico de los asentamientos misioneros y reconocimientos del territorio de los ayoreos como Tierras Comunitarias de Origen (TCO)}

\begin{tabular}{|c|c|c|c|}
\hline $\begin{array}{c}\text { Fecha aproximada } \\
\text { de asentamiento } \\
\text { misionero }\end{array}$ & $\begin{array}{l}\text { Hectáreas } \\
\text { Reconocidas } \\
\text { por ley }\end{array}$ & $\begin{array}{l}\text { Nombre de la Tierra } \\
\text { Comunitaria de Origen } \\
\text { (TCO) ubicación de } \\
\text { provincia }\end{array}$ & $\begin{array}{l}\text { Año de } \\
\text { titulación }\end{array}$ \\
\hline $\begin{array}{ll}\text { 1940-1947, } & 1948 \\
\text { (New Tribus) } & \\
\end{array}$ & 26.103 .9 & Tobité II (Chiquitos) & 1999 \\
\hline $\begin{array}{l}1950 \text { (Misión } \\
\text { Sudamericana) }\end{array}$ & 43.344 .4 & $\begin{array}{c}\text { Zapocó (Ñuflo de Chávez } \\
\text { y Velasco) }\end{array}$ & 1999 \\
\hline $\begin{array}{l}1952 \text { (Misión Bautista } \\
\text { Lettus) }\end{array}$ & 97.742 .9 & $\begin{array}{c}\text { Guaye-Rincón del Tigre } \\
\text { (Germán Busch) }\end{array}$ & 1999 \\
\hline 1957 (Misión católica) & 77.545 .2 & $\begin{array}{c}\text { Santa Teresita } \\
\text { (Chiquitos y Cordillera) }\end{array}$ & 1999 \\
\hline
\end{tabular}

Fuente: Fundación Tierra, "Subregión Chiquitana: Territorios Indígena Originario Campesinos Titulados"

$<$ http://territorios.ftierra.org/index.php?option =com content\&view=article\&id $=109$ \&Itemid=61> consultado el 3 de junio de 2020; Álvaro Díez, Compendio de etnias indígenas y ecoregiones: Amazonía, Oriente y Chaco [10 ed., Plural, 2011] 407 <books.google.es/books?isbn = 9995413833, 9789995413835> consultado el 3 de junio de 2020; José A. Martínez, Atlas territorios indígenas en Bolivia (situación de las Tierras Comunitarias de Origen (TCO's) [Plural, 2000] 115 $<$ https://www.bivica.org/files/territorios-indigenas-atlas.pdf> consultado el 15 de mayo de 2021; Marcelo Bórmida, cit. 10; Leonardo Tamburini, cit. 246, 250 y 254. Elaboración: propia.

\footnotetext{
14 Norma Casanova y otros, Compendio de etnias indígenas y ecoregiones, Nunca nos fuimos: Diagnostico sobre la situación socioeconómica de la población ayorea, chiquitana, guaraní, guaraya, yuracaré y mojeña en la ciudad de Santa Cruz de la Sierra [10 ed., 2014] 130

$<$ https://www.un.org/democracyfund/sites/www.un.org.democracyfund/files/bol10-403 libro nunca nos fuimos 0.pdf> consultado el 22 abril 2020
} 


\section{Cuadro No 2: Comunidades ayoreas existentes (2017)}

\begin{tabular}{|l|l|}
\hline \multicolumn{2}{|c|}{ Nombre de las Comunidades ayoreas } \\
\hline 1.- Poza Verde (1962) * & 13.- La Grama \\
\hline 2.- Urucú (1969) * & 14.- Yacuces \\
\hline 3.- Guidai Ichai* & 15.- Carmen* \\
\hline 4.- Motacú* & 16.- Porvenir \\
\hline 5.- 27 de Noviembre (1969) * & 17.- San José \\
\hline 6.- Tres cruces & 18.- Fortín (1977) $*$ \\
\hline 7.- Garay & 19.- Barrio Bolívar \\
\hline 8.- Corechi & 20.- Puesto Paz $(1977)^{*}$ \\
\hline 9.- Manantial & \multicolumn{1}{c|}{--} \\
\hline 10.- Pilay & \multicolumn{1}{c|}{--} \\
\hline 11.- Degui & \multicolumn{1}{c|}{--} \\
\hline 12.- Jogasui & \multicolumn{1}{|c|}{} \\
\hline
\end{tabular}

*Comunidades ayoreas levantadas por las misiones religiosas, en su mayoría tienen títulos.

Fuente: Enrique Herrera y otros, cit. 62; Ministerio de Educación, Estado Plurinacional de Bolivia, Currículo Regionalizado de la nación ayoreode [2017] 23 <https://www.minedu.gob.bo/files/publicaciones/upiip/CR_AYOREO_2017.pdf> consultado el 3 de junio de 2020

Elaboración: Propia

Para graficar las comunidades ayoreas tituladas, observamos en la figura No 1 lo siguiente:

- Las Tierras Comunitarias de Origen (TCO) tituladas de los ayoreos con el numeral 35 (Zapocó), 37 (Santa Teresita), 39 (Tobité II), 41 (Guaye-Rincón del Tigre).

- Estas TCO, se encuentran en el departamento de Santa CruzBolivia en la subregión Chiquitana y fueron levantadas por las misiones evangélicas y católicas. 
Figura No 1: Ubicación geográfica de las TCO ayoreas reconocidas

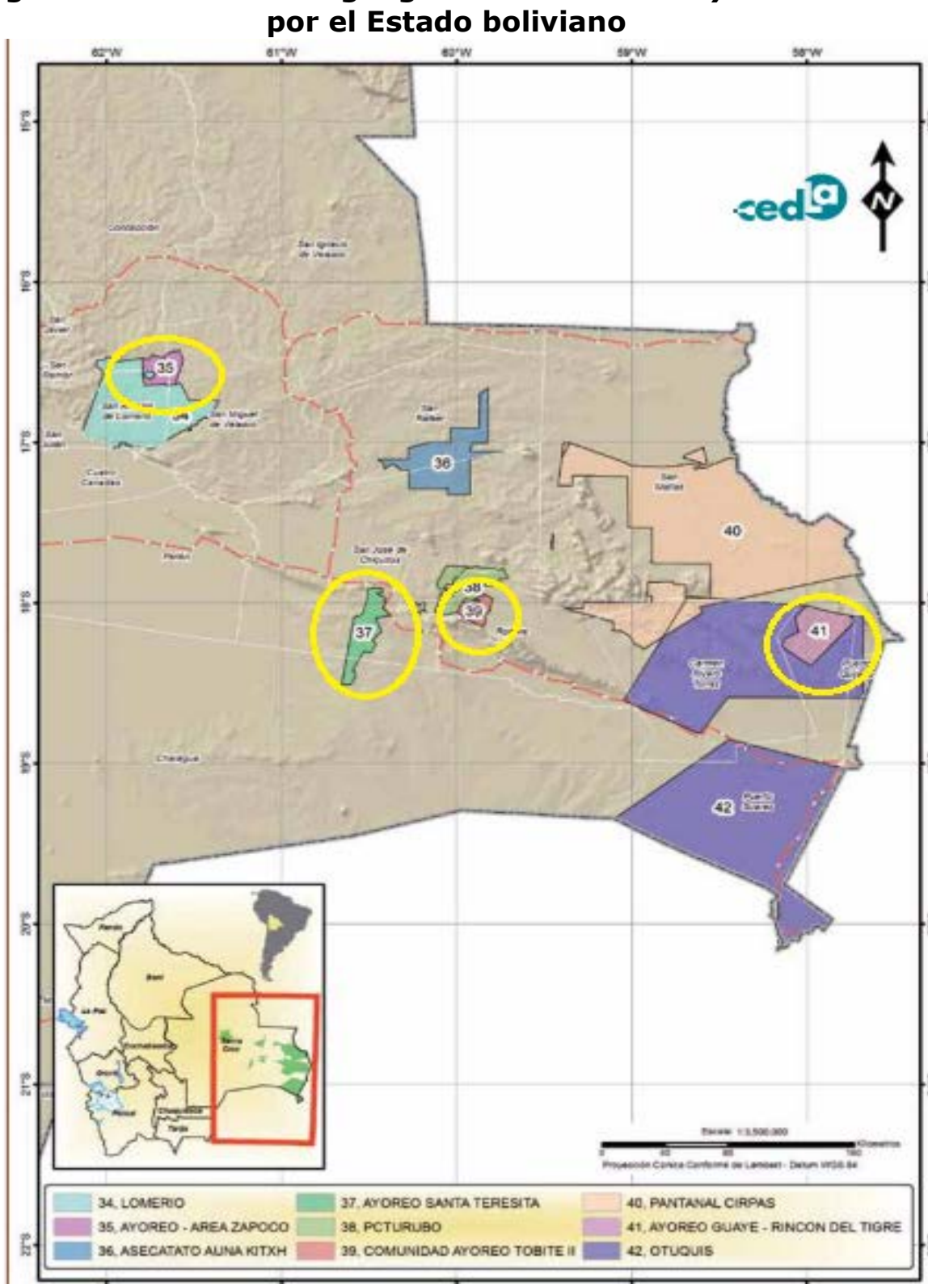

Fuente: Lizandra Paye y otros, Compendio de espaciomapas de TCO en tierras bajas, tenencia y aprovechamiento de recursos naturales en territorios indígenas [Cedla, 2011]

<http://biblioteca.clacso.edu.ar/Bolivia/cedla/20171023044839/pdf 249.pdf> consultado el 3 de junio de 2020

Elaboración: Propia

\section{2.- Historia de un reconocimiento territorial inconcluso}

Aunque los ayoreos fueron nómadas por tradición, ellos se fueron sedentarizando y ocuparon algunos territorios en el oriente boliviano con la ayuda de las misiones evangélicas y católicas, historia que comenzó en la década de los años cuarenta -como lo hemos visto anteriormente- este proceso de sedentarización comunitario logró 
constituir un hábitat geográfico donde desarrollaron sus principales actividades, es en este lugar donde ellos reconocieron su "territorio ancestral y de acceso tradicional".

Sin embargo, desde fines de la década de los setenta muchos de los líderes ayoreos expresaron la necesidad de tener en su poder los títulos de las comunidades, en especial de aquellos en los que estaban en manos de los misioneros; entonces los misioneros dudaron de entregarles ya sea de forma personal o comunitaria debido a los peligros que podría generar, excepto a la comunidad Tobité, donde la Misión New Tribus les entregó de forma comunal. Es decir, que si bien tenían un asentamiento consolidado este no estaba reconocido ante las autoridades bolivianas. Frente a esta situación los ayoreos empezaron a organizarse para consolidar y reivindicar su territorio.

Así, la década de los años ochenta fue un momento extraordinario de organización de los ayoreos porque en unidad con los chiquitanos, guarayos, guaraníes-izoceños, conformaron la Central de Pueblos y Comunidades Indígenas del Oriente Boliviano". En 1982 esta pasará a denominarse como "Confederación de Pueblos Indígenas de Bolivia (CIDOB)"15, su objetivo: conseguir el reconocimiento de los derechos sobre su tierra y territorio.

En 1987, se consolidó una de las más importantes organizaciones: la Central Ayorea Nativa del Oriente Boliviano (CANOB) quien juntamente con la organización no gubernamental "Apoyo Para el Campesino-Indígena del Oriente Boliviano" (APCOB) y la CIDOB plantearon en 1989, la primera demanda territorial con representación legal de la CANOB, al amparo de la Ley de Reforma Agraria de 1956. Esta demanda pidió la titulación de 25.000 has., el lugar demandado fue Guidai Ichai; sin embargo, la Resolución jurídica del Juez expresó que solo se dotaba de 12,628 has. esto no fue aceptado por los ayoreos quienes cuestionaron el mismo, finalmente esta demanda no prosperó debido a diversas circunstancias y después de estar paralizado por algún tiempo se perdió ${ }^{16}$.

Otro momento importante para buscar amparo en sus demandas territoriales fue cuando a través del Banco Mundial se financió un Proyecto de Tierras Bajas del Este, donde se creó una instancia especial el Componente Indígena (C.I.) para mitigar el impacto ambiental; el compromiso contemplaba reiniciar los trámites agrarios para ampliar y garantizar los derechos propietarios en las áreas de Puesto Paz, Zapocó y Rincón del Tigre y enfrentar los problemas de Puesto Paz, Gidai Ichai; en cinco años del proyecto, los trámites agrarios no avanzaron y

15 Cámara de Senadores, "Confederación de Pueblos Indígenas de Bolivia-CIDOB, 37 años defendiendo y promoviendo los derechos de los pueblos indígenas" $<$ https://web.senado.gob.bo/prensa/noticias/confederaci\%C3\%B3n-de-pueblosind\%C3\%ADgenas-de-bolivia-cidob-37-a\%C3\%B1os-defendiendo-y $>$ consultado el 3 de junio de 2020.

16 Enrique Herrera, "Identidades y territorios indígenas estrategias identitarias de los tacana y ayoreo frente a la ley INRA", cit., 62 y 63. 
algunos ayoreos vendieron sus terrenos, así Gidai Ichai quedó con una superficie de 700 has. ${ }^{17}$

La década de los años noventa significó para los ayoreos y otras naciones-aunque para ese tiempo fueron reconocidos como etniasmomentos históricos importantes en cuanto a la lucha por su territorio; en 1995 se creó la Coordinadora de Pueblos Étnicos de Santa Cruz (CPESC) la cual agrupó a los ayoroes, guarayos, chiquitanos y guaranís en conjunto a sus organizaciones. También durante esta época se observa que otra forma de revindicar su identidad y territorio fue a través de marchas, en esta década se realizaron dos muy importantes, la primera el año 1990, denominada "Marcha por el territorio y la dignidad de los pueblos nor-orientales de Bolivia" esta dio lugar a dos cambios importantes: a) la aprobación del Convenio No 169 de la Organización Internacional del Trabajo (O.I.T.) sobre pueblos indígenas y tribales, convertida en Ley No 1257 en el Estado Boliviano el año 1991. Posteriormente, se impulsó las reformas de la Constitución Política del Estado el año 1994, declarándose Bolivia como "multiétnica y pluricultural" (art.1) dejando atrás el monoculturalismo, en esta Constitución se reconoció el derecho a las tierras comunitarias de origen (art. 171 inc. 1); sin embargo, la misma limitará el derecho a la propiedad de los recursos naturales renovables.

La segunda fue en 1996, la "Marcha por el territorio, el desarrollo y la participación política de los pueblos indígenas ${ }^{18 "}$ en la cual se exigió la aprobación de la Ley del Servicio Nacional de Reforma Agraria (INRA) No 1715, misma que se logró. Ese mismo año, y antes de la promulgación de esta Ley presentaron una nueva demanda basada en una solicitud de ampliación de las cuatro áreas donde se encontraban los principales asentamientos ayoreos: Zapocó, Santa Teresita, Tobité y Rincón del Tigre, la observancia de presentar en estos lugares se debió a que no existía presión de particulares en las áreas solicitadas (tuvieron cuidado de no cometer los errores de la demanda de 1989) esta demanda es una de las más sustentadas técnicamente utilizando los nuevas normas promulgadas a favor de ellos (Ley No 1257, el art. 171 de la Constitución de 1994 y los Decretos Supremos que reconocieron los nueve territorio indígenas en $1991^{19}$.

Finalmente, la Ley INRA fue promulgada en octubre de 1996; sin embargo, al igual que la Constitución de 1994, se tuvo cuidado de no mencionar el concepto de "territorio indígena", sino que este fue englobado en la denominación de Tierras Comunitarias de Origen (TCO) el cual se define como:

\footnotetext{
17 Ibid., 60-67.

18 A partir de esta marcha se logró el reconocimiento de 33 Tierras Comunitarias de Origen (TCO) y la admisión de las primeras 16 demandas.

19 Enrique Herrera, "La nueva legislación agraria boliviana y la construcción identitaria indígena" [2006] 1441-1442 <https://halshs.archives-ouvertes.fr/halshs$\underline{00104295}$ > consultado el 2 de junio de 2020.
} 
"...los espacios geográficos que constituyen el hábitat de los pueblos y comunidades indígenas y originarias, a los cuales han tenido tradicionalmente acceso y donde mantienen y desarrollan sus propias formas de organización económica, social y cultural, de modo que aseguran su sobrevivencia y desarrollo. Son inalienables, indivisibles, irreversibles, colectivas, compuestas por comunidades 0 mancomunidades, inembargables e imprescriptibles... (Art. 41 inc. 5)".

La definición precedente tuvo influencia del Convenio No 169 de la O.I.T (art. 13, inc. II y 14) como lo reconoce esta misma Ley en su art. 3 parágrafo III; la Ley INRA si bien les da el derecho de participar del uso y aprovechamiento sostenible de los recursos naturales renovables existentes en su territorio, también limita esa potestad de acuerdo con lo establecido por la Constitución de 1994. Así, el año 1999 y en el marco de esta Ley las tierras solicitadas en 1996: Tobité II, Zapocó, Guaye-Rincón del Tigre, Santa Teresita fueron reconocidas como Tierras Comunitarias de Origen (TCO) un gran logro para todos ellos.

El avance en la reivindicación de su territorio continuo en la década de los dos mil - pues aún faltaba más territorios para ser reconocidos- en esta década se realizó la "Macha por la tierra el territorio y los recursos naturales (2000)" esta fue la tercera marcha en la que participaron; el año 2002 se realizó la cuarta "Marcha por la soberanía popular, el territorio y los recursos naturales" en la cual se propuso ir a la Asamblea Constituyente para pasar de ser un Estado excluyente desde 1825, a otro radicalmente distinto donde participarían los "excluidos" en la refundación del mismo.

La misma se llevó adelante los años 2006-2007, y culminó con la promulgación de la nueva Constitución Política del Estado el año 2009, esta Constitución declaro que Bolivia se reconocía como "plurinacional"; es decir, conformada por varias naciones, así se reconoció que Bolivia estaba conformada por 36 naciones las cuales eran preexistentes a la colonia-entre ellas la de los ayoreos además, este reconocimiento constitucional garantizo la libre determinación y el dominio ancestral sobre sus territorios ${ }^{20}$.

Sin embargo, pese a esta nueva forma de reconocimiento y hasta la actualidad, se observó que el avance en cuanto al reconocimiento del territorio de los ayoreos se vio menguada debido a cuatro factores: 1.- La nueva denominación ampliada a los ayoreos y otros como: "pueblos indígenas originario campesino".

2.-Cambio de nombre de Tierras Comunitarias de Origen (TCO) por Territorio Indígena Originario Campesino (TIOC).

3.- Aprovechamiento de la ampliación del denominativo en los hechos de parte de los "campesinos" para avasallar territorio y buscar reconocimiento individual a su propiedad dentro de las TIOC de los ayoreos.

20 Constitución Política del Estado de Bolivia de 2009 (CPE 2009) preámbulo, artículos 1 y 2. 
4.- Garantía constitucional a propietarios particulares cuyos predios se encuentren ubicados al interior de los TIOC.

Es decir, que la Constitución de 2009, aunque es un instrumento jurídico de adelantada para las "naciones ancestrales" reconocida a nivel nacional e internacional, muchas de sus normas internas se contraponen a las demandas no solo de los ayoreos sino también a la de otras naciones. Por otra parte, está claro que no ha habido avance en la demanda de reconocimiento de su territorio desde 1999 hacia la promulgación de la nueva Constitución (2009) 21.

Por tanto, las marchas de reivindicación territorial, recursos naturales y autonomía de parte de los ayoreos y otras nacionales ancestrales continuaron llevándose; hasta el año 2011 se compatibilizo ocho marchas en total desde el inicio en $1990^{22}$.

\section{2.- ALGUNOS FACTORES DE HECHO Y DE DERECHO QUE PERMITEN EL AVASALLAMIENTO EN EL TERRITORIO AYOREOS Y DIFICULTADES EN EL AVANCE DEL RECONOCIMIENTO TERRITORIAL}

A partir de la vigencia de la Ley N01715 (INRA) en 1996, su posterior modificación a través de la Ley No 3545 de Reconducción Comunitaria de Reforma Agraria de 2006, y su reglamentación con el Decreto Supremo 29.215 de 2007, no existió hasta ese tiempo ningún avance en cuanto a nuevas titulaciones de los territorios ayoreos. Posteriormente, la nueva Constitución Política del Estado del año 2009 realizó cambios en cuanto a la nueva forma de denominación de las Tierras Comunitarias de Origen (TCO), por Territorio Indígena Originario Campesino (TIOC), estos cambios originaron nuevas adversidades en el avance de la titulación del territorio de los ayoreos; por una parte, entraban administrativamente el cambio de TCO para TIOC, lo cual hasta la fecha no se logró consolidar.

Jurídicamente ser una TCO no es lo mismo que ser una TIOC la cual consolida otro tipo de derechos como la autonomía, es decir el propio gobierno y la libre determinación. Sin embargo, mientras se resuelve el tema administrativo de cambio de nombre el cual implica una burocracia amplia y necesaria. La ampliación denominativa de TIOC la cual incluye al "campesino" en esta forma de reconocimiento, acarreó dos problemas; por una, que las personas que se reconocen bajo este denominativo empiecen a migrar e invadan el territorio de los ayoreos. Esta invasión da como resultado el avasallamiento y la deforestación del hábitat de las comunidades ayoreas. A continuación,

\footnotetext{
21 El contexto del artículo se describe hasta el año 2021.

22 Pieb, "Marchas de los pueblos indígenas, un aprendizaje político para las nuevas generaciones" Periódico digital de investigación sobre Bolivia [La Paz, 2 de marzo de 2012] <https://www.pieb.com.bo/sipieb notas.php?idn $=6600>$ consultado el 2 de junio de 2020.
} 
otros factores detectados para la no consolidación de los territorios de los ayoreos.

\section{1.- La nueva denominación "ampliada" a los ayoreos como "naciones y pueblos indígenas originario campesino"}

La Constitución del año 2009, reconoce a los ayoreos y a otras naciones ancestrales como "naciones y pueblos indígenas originarios campesino", el cual es una sumatoria del proceso histórico que han vivido otras naciones en Bolivia, por ejemplo, los aymaras y quechuas. Al contrario, los ayoreos tienen otro tipo de trasfondo histórico que no necesariamente se adecua a las denominaciones mencionadas. Por ejemplo, durante la vigencia de la Ley de Reforma Agraria de 1953 y hasta antes de 1994 ellos fueron llamados "silvícolas".

De todas estas formas de reconocimiento (amplio y anónimo), el que les ha traído más conflicto hasta ahora, es el denominativo "campesino" este reconocimiento a su identidad, no es parte de ellos, puesto que si bien se dedican a la producción de alimentos, el mismo es para autoabastecerse.

Hay una diferencia entre autoidentificarse como ayoreo o como indígena, pueblo indígena, originario; puesto que el primero da lugar a la libre determinación y a la propia autoidentificación, en cambio los denominativos más amplios llevan a los ayoreos a una anonimidad, a una identidad ajena y aun desconocimiento de quienes son ellos.

Siendo que la Constitución de 2009 les reconoce también como "nación" con derecho a la libre autodeterminación (art. 2), es correcto que se les reconozca de esta forma, aunque ni esta denominación les coadyuba en sus reivindicaciones puesta que se vuelve a caer en la identificación de parte de otro.

\section{2.- Cambio de nombre de Tierras Comunitarias de Origen (TCO) a Territorio Indígena Originario Campesino (TIOC)}

Su lucha histórica para el reconocimiento de cuatro de sus comunidades como Tierras Comunitarias de Origen (TCO) fue un largo proceso (como se ha descrito); sin embargo, con la nueva nomenclatura constitucional ese avance se ve menguado puesto que ahora se pide que las mismas puedan pasar por un proceso administrativo, como lo describe el D.S. 0727 para ser denominadas Territorios Indígenas Originarios Campesinos (TIOC).

No se tiene datos de que las TCO ayoreas hayan logrado el cambio de denominación a TIOC, debido a los diversos requisitos. Y aunque su derecho territorial esta resguardado; para adelante se ve difícil cumplir con lo que la ley demanda. También cabe destacar que una TCO no es lo mismo que una TIOC ambos tienen diferencias y les resguardan diferentes tipos de derechos, en el caso de la TIOC da derecho a un gobierno autónomo, muy relacionado a lo que sería la libre determinación; es decir, convertirse en una Autonomía Indígena 
Originaria Campesina (AIOC), sin embargo, existe aún la limitación en el uso y aprovechamiento de los recursos naturales renovables en las condiciones que determina la ley, lo cual significa que no se está avanzando hacia una real determinación. A continuación, en el Cuadro No 3, se muestra ambos conceptos de TCO y TIOC, en el cual se observará las diferencias.

\section{Cuadro No 3 Definiciones TCO y TIOC}

\begin{tabular}{|c|c|}
\hline $\begin{array}{l}\text { Definición de TCO de } \\
\text { acuerdo con la Ley No } 1715 \\
\text { (INRA) }\end{array}$ & $\begin{array}{l}\text { Definición de TIOC de acuerdo } \\
\text { con la Ley No } 031 \text { Marco de } \\
\text { Autonomías y Descentralización }\end{array}$ \\
\hline $\begin{array}{l}\text { "...los espacios geográficos que } \\
\text { constituyen el hábitat de los pueblos } \\
\text { y comunidades indígenas y } \\
\text { originarias, a los cuales han tenido } \\
\text { tradicionalmente acceso y donde } \\
\text { mantienen y desarrollan sus propias } \\
\text { formas de organización económica, } \\
\text { social y cultural, de modo que } \\
\text { aseguran su sobrevivencia y } \\
\text { desarrollo. Son inalienables, } \\
\text { indivisibles, irreversibles, colectivas, } \\
\text { compuestas por comunidades o } \\
\text { mancomunidades, inembargables e } \\
\text { imprescriptibles }\end{array}$ & $\begin{array}{l}\text { "...Es el territorio ancestral sobre el cual se } \\
\text { constituyeron las tierras colectivas o } \\
\text { comunitarias de origen, debidamente } \\
\text { consolidadas conforme a ley, y que ha } \\
\text { adquirido esta categoría mediante el } \\
\text { procedimiento correspondiente ante la } \\
\text { autoridad agraria...En aquellos casos en } \\
\text { que el territorio indígena originario } \\
\text { campesino cumpla los requisitos y } \\
\text { procedimientos establecidos en la presente } \\
\text { norma, se conformará en éste un gobierno } \\
\text { autónomo indígena originario campesino. } \\
\text { Este territorio será aprobado por ley como } \\
\text { unidad territorial, adquiriendo así un doble } \\
\text { carácter..." }\end{array}$ \\
\hline
\end{tabular}

Fuente: Ley No 1715 de 1996, Ley No 031 de 2010.

Elaboración: propia

Por otra parte, esta ampliación de denominativos de TCO a TIOC en la cual se incluye a los "campesinos" abrió la puerta para estos se asienten sobre los territorios de los ayoreos; el Estado justifica la terminología respondiendo que solo se ha unificado visiones como la "campesina e indígena" sobre el territorio, como un espacio para la reproducción cultural y en el que también se ejerce la gobernabilidad sobre la tierra y los recursos naturales.

Esta es una interpretación equivocada porque la visión de los ayoreos es totalmente distinta a la "campesina", el primero tiene una visión más integral sobre el uso y aprovechamiento de su territorio, donde desarrollan actividades de cacería y producen agricultura de subsistencia de pequeña escala y recolección (por su estilo de vida). Esto hace pensar que sus territorios son espacios vacíos o tierras baldías, y propicia la ocupación de campesinos migrantes.

Mientras que los campesinos e interculturales tienen una visión que apunta al beneficio agrícola a través de la siembra y la comercialización en el mercado, para ello deben deforestar los bosques causando la degradación de los suelos, más cuando la producción de soya está en auge. 
El efecto de este cambio de denominación a "Tierras Indígenas Originarias Campesinas" llegó a afectar a la TCO Zapocó en el cual se ha constatado que campesinos e interculturales migrantes de otras regiones en el proceso de su migración crean comunidad, posteriormente realizan desmontes ilegales, los cuales sirven para aprovechamiento y negocio de la madera de forma ilegal, también efectúan cultivos, venden la tierra a terceros y luego se trasladan a otro lugar; incluso han llegado a solicitar estas tierras al Instituto Nacional de Reforma Agraria (INRA) ${ }^{23}$.

\section{3.- Garantía constitucional a propietarios particulares cuyos predios se encuentren ubicados al interior de la TIOC}

Las restricciones formales se ven ampliadas cuando "terceros", es decir todos aquellos que no forman parte de la comunidad ayorea, tales como: ganaderos, comunidades no miembros de las TCO, propietarios de haciendas medianas y grandes, agropecuarios, forestales maderables, demandan la titularidad de las superficies, consolidando y ampliando sus posesiones en detrimento de los territorios de los ayoreos.

La importancia de estos terceros es que no son una población minoritaria, sino que van creciendo en el afán mercantilista además de que sus propiedades se van conformando en base a los territorios de los ayoreos, muchos de ellos se ven obligados a venderles su parcela por sus paupérrimos ingresos o entablan relaciones de trabajo en condiciones de dependencia y subordinación ${ }^{24}$.

El art. 394 en el parágrafo I de la Constitución de 2009 expresa: "...se garantizan los derechos legalmente adquiridos por propietarios particulares cuyos predios se encuentren ubicados al interior de territorios indígena originario campesino..." la norma menciona que se resguarda la propiedad de los particulares, este precepto es aprovechado por los terceros para avanzar en sus intereses privados.

\section{3.- CONCLUSIONES}

Los ayoreos son una "nación" con derecho a la libre determinación y dominio ancestral sobre su territorio como lo ha

\footnotetext{
23 Eduardo Franco, "Bolivia: pueblo ayoreo denuncia el ingreso de taladores ilegales a su territorio" Mongabay Latam $[20$ de abril de 2017] $<$ https://es.mongabay.com/2017/04/bolivia-pueblo-ayoreo-denuncia-ingresotaladores-ilegales-territorio/ >consultado 20 de abril de 2020.

24 Lizandra Paye y otros, Compendio de espaciomapas de TCO en tierras bajas tenencia y aprovechamiento de recursos naturales en territorios indígenas [Cedla 2011] 12.

<http://biblioteca.clacso.edu.ar/Bolivia/cedla/20171023044839/pdf_249.pdf> consultado el 17 de mayo de 2021.
} 
reconocido la Constitución del año 2009, como tal, es justo que se les otorgué todos los mecanismos para seguir en el reconocimiento y titulación de su territorio. Estos mecanismos deben ir desde facilitar los trámites que son simplemente administrativos (Ley No 0727) a través del cambio de denominación de TCO a TIOC, y no como hasta ahora que se torna en un obstáculo. También se debe consolidar los territorios ayoreos que aún no han sido titulados debido a la interferencia de terceros, siendo que como reconoce la Constitución ellos tienen el dominio ancestral de su territorio.

El reconocimiento del territorio ayoreo debe conllevar el acceso y el reconocimiento al derecho del suelo, subsuelo y no como hasta ahora que solo se ha realizado un reconocimiento aparente ante la comunidad nacional e internacional, al reconocerse como un Estado plurinacional, pero que a la hora del reconocimiento en los hechos pone limitaciones jurídicas sectoriales, dejando de lado los principios bajo los que se fundó el Estado Boliviano en la Asamblea Constituyente uno de los cuales fue el principio de "pluralidad" el cual se transmuta en pluralismo político, económico, jurídico, cultural y lingüístico.

Las marchas de los ayoreos que en conjunto realizaron con otras naciones ancestrales que habitan en el oriente boliviano, fueron y son fundamentales para el avance en el reconocimiento de sus territorios, aunque la última década las mismas no han logrado sus objetivos, estas se constituyen como una forma para salir de la invisibilidad y pedir de forma más contundente sus derechos territoriales y autonomía. La marcha más importante para los ayoreos fue la "II Marcha por el territorio, los derechos de participación política y el desarrollo" (1996) la cual presiono para que se atendiesen sus demandas y posteriormente fueran reconocidas cuatro de sus comunidades como TCO.

La presencia de terceros: campesinos, interculturales migrantes, productores pequeños y medianos en Tierras Comunitarias de Origen de los ayoreos se ve incrementada por el cambio de denominación de Tierras Comunitarias de Origen (TCO) por Territorio Indígena Originario Campesino (TIOC) en la Constitución de 2009. A partir de esto se ha notado un avasallamiento en sus territorios, como lo ha denunciado la TCO Zapocó, además existe garantía constitucional a propietarios particulares cuyos predios se encuentren ubicados al interior de la TIOC, la cual es aprovechado por los terceros para ingresar ilegalmente a las TCO ayoreas y consolidan su derecho propietario por la inercia de las autoridades y la acción limitada que tienen los ayoreos.

Aún existen comunidades ayoreas generadas por la intervención de misiones religiosas que no han logrado ser tituladas aún, entre estas se encuentran Poza Verde (1962), 27 de Noviembre (1969), Urucú (1969), Puesto Paz (1977) y Fortín (1977), se presume que tienen los títulos; no se conoce exactamente las causas, sin embargo, la oposición de terceros que habitan en estas comunidades es un factor preponderante como ocurrió en su demanda de 1989 con Guidai Ichai. 
Los ayoreos se encuentran en una situación adversa y controvertida en cuanto al avance de la titulación de sus territorios y se convierten en un estorbo en cuanto al avance de una economía extractiva en lo forestal para la obtención de recursos naturales. Aunque formalmente son reconocidos como "nación", esta denominación se convierte en un obstáculo a la hora de reconocer sus derechos territoriales.

La denominación "nación" hacia los ayoreos dentro de un Estado que se reconoce como plurinacional no es real, los ayoreos y otras naciones ancestrales han pasado por diversas etapas en su reconocimiento desde ser denominados aborígenes, silvícolas, indios, indígenas, pueblos indígenas, campesinos, etnias, hasta convertirse en "nación" bajo el pensamiento occidental; sin embargo, esta nueva denominación no otorga los derechos plasmados en la Constitución de 2009. Así se convierte otra vez, en una nueva fase, donde cualquiera sea la política de gobierno que impere (corte "indígena" o no), no es posible avanzar un paso más hacia el verdadero reconocimiento de lo que esto implica; por tanto, hay un desfase entre lo escrito y lo real.

\section{4.- BIBLIOGRAFÍA}

Administradora Boliviana de Carreteras, Proyecto carretero del corredor conector de Santa Cruz-SCRCCP plan de pueblos indígenas (PPI) comunidades indígenas Chiquitanas y Ayoreode del área de influencia del proyecto [2015] 14 $<$ http://documents.worldbank.org/curated/en/4189714682846 60552/pdf/SFG1743-REVISED-IPP-SPANISH-P152281Box396261B-PUBLIC-Disclosed-5-25-2016.pdf>consultado el 20 de abril de 2020.

Bórmida M, Ergon y Mito. Una hermenéutica de la cultura material de los Ayoreo del Chaco Boreal [CIAFIC 2005] 10 <http://www.ciafic.edu.ar/documentos/Archivos III 1 2005.pd f>_consultado el 4 de abril de 2020.

Casanova N, García I, Gutiérrez JC, Aeguazu D, Nunca nos fuimos: Diagnostico sobre la situación socioeconómica de la población ayorea, chiquitana, guaraní, guaraya, yuracaré y mojeña en la ciudad de Santa Cruz de la Sierra [10 ed., 2014] 130 < https://www.un.org/democracyfund/sites/www.un.org.democra cyfund/files/bol-10-403 libro nunca nos fuimos $0 . p d f>$ consultado el 22 abril 2020.

Díez A, Compendio de etnias indígenas y ecoregiones: Amazonía, Oriente y Chaco $\left[1^{0}\right.$ ed., Plural, 2011] 407 <books.google.es/books?isbn = 9995413833, 9789995413835> consultado el 3 de junio de 2020.

Estado Plurinacional de Bolivia, Censo de población y vivienda 2012 Bolivia Características de la Población (2015) 29 y 30 <https://www.ine.gob.bo/index.php/publicaciones/censo-de- 
poblacion-y-vivienda-2012-caracteristicas-de-la-poblacion/> consultado el 30 octubre 2019.

Franco E, "Bolivia: pueblo ayoreo denuncia el ingreso de taladores ilegales a su territorio" Mongabay Latam [20 de abril de 2017] <https://es.mongabay.com/2017/04/bolivia-pueblo-ayoreodenuncia-ingreso-taladores-ilegales-territorio/> consultado 20 de abril de 2020

Fundación Tierra, "Subregión Chiquitana: Territorios Indígena Originario Campesinos Titulados"

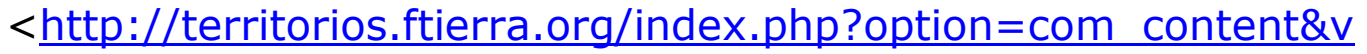
iew $=$ article\&id $=109 \&$ Itemid $=61>$ consultado el 3 de junio de 2020.

Herrera E, Cárdenas C, Terceros E, Identidades y territorios indígenas estrategias identitarias de los tacana y ayoreo frente a la ley INRA [Ana María Lema, 2003] 62 < http://www.pieb.com.bo/2016/BPIEB/BPIEB 1656 Identidad es.pdf $>$ consultado el 1 junio 2020

Herrera $\mathrm{E}$, "La nueva legislación agraria boliviana y la construcción identitaria indígena" [2006]

1441-1442

$<$ https://halshs.archives-ouvertes.fr/halshs-

00104295 > consultado el 2 de junio de 2020.

Nostas M, Sanabria C, Detrás del cristal con que se mira: Mujeres ayoreas-ayoredie, órdenes normativos e interlegalidad [10 ed., 2009]

<http://www.coordinadoradelamujer.org.bo/observatorio/archi vos/publicaciones/libro mujeres ayoreasayoredie ordenes nor mativos e interlegalidadc 273.pdf> consultado el 31 mayo 2020.

Lovera M, Kang J, Alarcón M y De la Cruz L, La situación de los ayoreos aislados en Bolivia y en las zonas transfronterizas con Paraguay [Informe 2016, 2017] 5 <https://www.iniciativaamotocodie.org/wpcontent/uploads/2019/08/InformeAisladosZonaFronteraPYBO.pdf >consultado el 10 de abril de 2020.

Martínez J, Atlas territorios indígenas en Bolivia (situación de las Tierras Comunitarias de Origen (TCO's) [Plural, 2000] 115 <https://www.bivica.org/files/territorios-indigenas-atlas.pdf> consultado el 15 de mayo de 2021.

Ministerio de Educación, Estado Plurinacional de Bolivia, Currículo Regionalizado de la nación ayoreode [2017] 23 <https://www.minedu.gob.bo/files/publicaciones/upiip/CR_AYO REO_2017.pdf>

consultado el 3 de junio de 2020.

Schmeda-Hirschmann G, "Etnobotánica Ayoreo. Contribución al estudio de 1a flora y vegetación del Chaco" [1998] 53 Candollea $1-50$

<https://www.researchgate.net/profile/Guillermo SchmedaHirschmann/publication/277204260_Etnobotanica_Ayoreo_Cont 
ribucion al estudio de la flora y vegetacion del Chaco/links/ 55b62a1808aed621de03169e/Etnobotanica-Ayoreo-

Contribucion-al-estudio-de-la-flora-y-vegetacion-del-

Chaco.pdf>consultado el 31 de mayo de 2020.

Lizandra Paye L, Arteaga W, Ramírez N, Ormachea E, Compendio de espaciomapas de TCO en tierras bajas tenencia y aprovechamiento de recursos naturales en territorios indígenas [Cedla 2011] 12 http://biblioteca.clacso.edu.ar/Bolivia/cedla/20171023044839/ pdf_249.pdf> consultado el 17 de mayo de 2021.

Pieb, "Marchas de los pueblos indígenas, un aprendizaje político para las nuevas generaciones" Periódico digital de investigación sobre Bolivia [La Paz, 2 de marzo de 2012] $<$ https://www.pieb.com.bo/sipieb notas.php?idn $=6600>$ consul tado el 2 de junio de 2020.

Cámara de Senadores, "Confederación de Pueblos Indígenas de Bolivia-CIDOB, 37 años defendiendo y promoviendo los derechos de los pueblos indígenas" $<$ https://web.senado.gob.bo/prensa/noticias/confederaci\%C3\% B3n-de-pueblos-ind\%C3\%ADgenas-de-bolivia-cidob-37a\%C3\%B1os-defendiendo-y>consultado el 3 de junio de 2020.

Tamburini L, Atlas Sociopolítico sobre los territorios indígenas en las tierras bajas de Bolivia [IWGIA, 2019] 246, 250 y 254 $<$ https://www.iwgia.org/images/documentos/Libros/ATLAS\%20 2019.pdf>

consultado el 1 de junio de 2020.

Zanardini J, "Vida y misterio de los indios Moros Ayoreos" [1981] 16 Suplemento antropológico, $<$ http://www.bibvirtual.ucb.edu.bo:8000/etnias/digital/106001 469.pd>consultado el 31 de mayo de 2020. 